\title{
PAULO FREIRE E A EDUCAÇÃO DE JOVENS E ADULTOS: SENTIDOS ATRIBUÍDOS PELOS ALUNOS PARA A PERMANÊNCIA NA EJA
}

\author{
JosIANE REGINA DE SOUZA BUZIOLI \\ Elvira Cristina Martins TASSONI \\ Pontifícia Universidade Católica de Campinas (PUC-Campinas), Campinas, São Paulo, Brasil
}

\begin{abstract}
Resumo: Tomando o legado de Paulo Freire como referência, apresentamos uma pesquisa que teve o objetivo de investigar o que afeta os alunos da EJA, anos iniciais, de forma a potencializar a vontade de se manterem estudando, permanecendo na escola por mais tempo, minimizando a evasão. Trata-se de uma pesquisa empírica realizada em três classes de EJA (anos iniciais), no município de Campinas/SP. Os procedimentos metodológicos envolveram a observação em sala de aula e a realização de grupos focais com 31 alunos. A análise explorou os sentidos atribuídos pelos participantes às suas experiências pessoais e escolares. Os fatores que contribuem para a permanência na EJA são: o desejo de inserção cultural e a percepção de que estão aprendendo. As influências da família e do trabalho constituíram tanto motivos de impedimentos como para a permanência.
\end{abstract}

Palavras-chave: Afetos e EJA. Ensino e Aprendizagem. Escola e Inserção Cultural. Permanência e Evasão.

\section{INTRODUÇÃO}

A alfabetização de jovens e adultos nem sempre foi vista como um direito no Brasil. As primeiras décadas do século XX são lembradas por mobilizações em diversas esferas da sociedade em relação à alfabetização de adultos, visto que os dados apresentados pelo censo de 1890 mostraram que $80 \%$ da população brasileira era analfabeta. Muitas foram as campanhas pela alfabetização no período.

Paulo Freire esteve diretamente envolvido em vários movimentos educacionais, especialmente nas décadas de 1950 e 1960, e inspirou outros tantos, como o Movimento de Educação de Base, a Conferência Nacional de Bispos do Brasil, os Centros Populares de Cultura, organizados pela União Nacional dos Estudantes, a Campanha de Educação Popular. Esses movimentos surgiram em várias regiões do país, mas foi no Nordeste que se concentrou a maior parte deles. Naquela época, metade da população era excluída da vida política por ser analfabeta. $\mathrm{O}$ analfabetismo era consequência de uma sociedade injusta e não igualitária. Assim, a alfabetização de adultos deveria auxiliar na transformação da realidade social.

Paulo Freire (2019) propõe uma educação dialógica e não bancária, trazendo a realidade do educando de forma central no processo de alfabetização. Sempre partindo dessa realidade e de sua experiência, a proposta pautava-se pela seleção de palavras geradoras, que pudessem desencadear a problematização da realidade, de forma a 
superá-la e, ao mesmo tempo, servisse como possibilitadoras do ensino. Com isso, Freire (1975) traz a ideia de que a educação suscita a conscientização do homem, possibilitando a evolução de uma consciência ingênua - caracterizada por simplicidade na interpretação dos problemas e tendência ao conformismo - para uma consciência crítica - que se caracterizava pela profundidade na interpretação de problemas e uma maior dose de racionalidade.

Segundo Beisiegel (2010), Freire afirmava que:

\begin{abstract}
[...] somente a formação e o desenvolvimento de uma consciência capaz de apreender criticamente as características dessa realidade particular possibilitariam o exercício de sua atuação criadora. A formação e o desenvolvimento dessa consciência, por sua vez, dependiam do mergulho do homem na sua própria realidade, impunham o comprometimento com sua circunstância. Assim, a humanização do homem, isto é, a plena realização do homem enquanto criador de cultura e determinador de suas condições de existência passava, necessariamente, pela clarificação da consciência do homem - coisa que somente poderia ocorrer no âmbito do crescente comprometimento do homem com a sua realidade. E situavam-se exatamente aí as funções do processo educativo (BEISIEGEL, 2010, p. 30).
\end{abstract}

Para Freire (2019), o diálogo entre os homens apresenta-se como fundamental na educação que visa à construção de personalidades democráticas. O autor valorizava o sujeito analfabeto, mostrando que este era produtor de conhecimento, defendendo que "a leitura de mundo precede a leitura da palavra" (FREIRE, 1989, p. 24). Trazia uma ideia de alfabetização de adultos diferenciada, baseada nos círculos populares de cultura, que, naquele período, alicerçavam-se na educação popular. Defendia o diálogo e a interação como princípios para garantir a libertação do aluno e o direito à educação básica (FREIRE, 2019).

Freire (2019) apresentava a educação com duas funções: habilitar, com a intenção de preparar de forma técnica e cientificamente, o homem para o mercado de trabalho, e atender às necessidades existentes na sociedade. Para atingir seu objetivo, assumia como princípios norteadores a leitura do mundo e as experiências de vida, defendendo uma alfabetização que parte da realidade concreta do homem e possibilita, além do ensino da leitura e escrita, a conquista da liberdade.

Paulo Freire foi responsável por criar o Plano Nacional de Alfabetização, aprovado em 1964 e abolido pelo Golpe Militar, sendo substituído pelo Movimento Brasileiro de Alfabetização (MOBRAL). Criado em 1967, o MOBRAL foi uma ação elaborada pelo regime militar no Brasil (1964-1985) e funcionava como uma estrutura paralela e autônoma em relação ao Ministério da Educação. Na época, foi realizada uma campanha nacional, convocando a população a fazer a sua parte com o bordão: "você também é responsável, então me ensine a escrever, eu tenho a minha mão domável, eu sinto a sede do saber". O MOBRAL mobilizava a sociedade com a despreocupação com o fazer docente, pois qualquer um que soubesse ler e escrever poderia ensinar. Extinto em 1985 com a Nova República e o fim do Regime Militar, surge, em seu lugar, a Fundação 
Educar (HADDAD; DI PIERRO, 2000), vinculada ao Ministério da Educação, com a função de supervisionar e acompanhar as instituições e secretarias que recebiam os recursos transferidos para a execução de seus programas.

Em 1988, a Constituição Federal concede o direto à educação aos que não haviam frequentado ou concluído o ensino fundamental (BRASIL, 1988). Nesse período, muitas práticas e metodologias de ensino passaram a ser utilizadas. No entanto, em 1990, o governo Collor extinguiu a Fundação Educar e o governo federal, a partir de então, deixou de ser o articulador de política de alfabetização de jovens e adultos no país.

Foi um ano antes, em 1989, que a Secretaria Municipal de Educação da cidade de São Paulo, com Paulo Freire na gestão, lançou o Movimento de Alfabetização (MOVA), que procurava envolver o poder público e a iniciativa civil na alfabetização de jovens e adultos. O MOVA tinha como ideia olhar o sujeito não alfabetizado de forma diferenciada, elaborando proposta a partir do contexto social, tornando esse sujeito corresponsável no processo de formação. A proposta iniciada com Paulo Freire previa uma estrutura de funcionamento adotada até os dias atuais em muitos municípios do país. As salas de aula estão instaladas onde há pouca oferta de escolas e grande demanda. Por meio de convênios entre as prefeituras e entidades e associações de diferentes naturezas, espaços em igrejas, creches, associações e empresas são utilizados para promover a todos os jovens e adultos a escolaridade, combatendo o preconceito em relação ao analfabetismo. As prefeituras custeiam as despesas dos educadores e as entidades se responsabilizam pelo local das aulas. A grande contribuição desse modelo implantado na cidade de São Paulo, desde o tempo em que Paulo Freire estava à frente da Secretaria de Educação, foi a possibilidade de acesso facilitado aos espaços educativos, poupando o custo e o desgaste de transporte. Além disso, a proposta pedagógica se destacava pela capacidade de se adequar à realidade e às necessidades dos alunos.

Com inspiração no MOVA criado por Paulo Freire, o Instituto Paulo Freire, desde 2003, é responsável pelo Projeto MOVA-Brasil, que mantém os mesmos princípios e finalidades do movimento original - "a inclusão social, e a garantia do direito humano à educação, a redução do analfabetismo no Brasil, a geração de trabalho e renda e, com isso, contribuir para a construção de políticas públicas para a Educação de Jovens e Adultos (EJA)" (MOVA-BRASIL, n.d.). A proposta pedagógica mantém os temas geradores como orientadores dos conteúdos.

Mesmo assim, em pleno século XXI, ainda nos deparamos com elevados índices de analfabetismo no país. De acordo com dados do Instituto Brasileiro de Geografia e Estatística (IBGE), "no Brasil, segundo a Pesquisa Nacional por Amostra de Domicílios Contínua (PNAD Contínua) 2019, a taxa de analfabetismo das pessoas de 15 anos ou mais de idade foi estimada em 6,6\% (11 milhões de analfabetos)" (IBGE EDUCA, n.d.).

Conforme encontrado no site do Centro de Alfabetização, Leitura e Escrita (CEALE) da Faculdade de Educação da UFMG, o conceito de analfabeto, segundo a etimologia da palavra, refere-se à - a (negação) + alfabeto = sem alfabeto. Ou seja, "designa qualquer pessoa que não conheça o alfabeto ou que não saiba ler e escrever, e analfabetismo, à condição de quem não conheça o alfabeto ou não saiba ler e escrever" (FERRARO, n.d.). 
O sujeito analfabeto é aquele que não frequentou o espaço escolar, seja por precisar garantir ou auxiliar no sustento da família por meio do trabalho, seja por apresentar uma história de insucesso escolar. Um sujeito considerado incapaz, ignorante e dependente reforça a imagem do sujeito que precisa de alguém para tirá-lo da ignorância. Esse tipo de representação em suas diversas variações gera a baixa autoestima dos não alfabetizados, que apesar de viverem dignamente, incorporam o discurso de inferioridade a eles atribuído (ALMEIDA, 2003).

A concepção de alfabetização está vinculada à possibilidade de crescimento pessoal ou social. Por muito tempo, a ação de alfabetizar foi vista como possibilidade de "iluminar" o sujeito, como se o analfabeto fosse ignorante e não possuísse nenhum tipo de conhecimento. Já a concepção de alfabetizador foi marcada na história por descompromisso com a didática. Qualquer pessoa que apresentasse domínio na leitura e na escrita, que demonstrasse paciência e vontade de ensinar, poderia se tornar um alfabetizador (ALBUQUERQUE; LEAL, 2006).

Muitas foram as campanhas para o fim do analfabetismo no decorrer da história, mas a maioria foi marcada por improvisação e por transposição de métodos e materiais. O que era usado para ensinar as crianças a ler e a escrever foi usado também para ensinar os adultos, sem qualquer consideração às especificidades deste público.

O caminho da Educação de Jovens e Adultos no Brasil evidencia a educação da camada popular. Paulo Freire (2019), em sua obra Pedagogia do Oprimido, traz a importância de se desenvolver uma Educação de Jovens e Adultos voltada para a criticidade, possibilitando a transformação social. Segundo o autor,

[...] alfabetizar-se não é aprender a repetir palavras, mas a dizer a sua palavra, criadora de cultura. A cultura letrada conscientiza a cultura: a consciência historiadora automanifesta à consciência sua condição essencial de condição histórica. Ensinar a ler as palavras ditas e ditadas é uma forma de mistificar as consciências, despersonalizando-as na repetição - é a técnica de propaganda massificadora. Aprender a dizer a sua palavra é toda a pedagogia, e também toda antropologia (FREIRE, 2019, p. 25).

Em outras palavras, a alfabetização exerce uma função transformadora para além do contexto escolar e a relação dialógica se faz caminho para a relação coletiva dos homens, possibilitando a troca recíproca e a ressignificação das experiências vivenciadas por cada sujeito.

As discussões sobre o ensino e as práticas pedagógicas voltadas para alfabetização de jovens e adultos têm ganhado espaço no contexto educacional e evidenciam que, para se obter melhores resultados e avanços no processo de ensino e aprendizagem, as práticas pedagógicas devem partir do contexto de vida dos sujeitos. Assim, para ensinar um jovem ou adulto a ler e escrever são necessários diversos saberes, que levam em conta as peculiaridades de cada sujeito, com propostas pedagógicas adequadas e metodologias apropriadas para a educação desse público, 
considerando o sujeito, a sua história e os conhecimentos que produz. Nesse mesmo sentido, Freire $(1996,2019)$ afirma que as práticas pedagógicas devem estar relacionadas e deve-se considerar o contexto de vida dos alunos, levando-os a se compreenderem como indivíduos inseridos em uma cultura.

Segundo Soares e Pedroso (2013),

[...] cabe destacar que a singularidade dessa modalidade educativa em relação às outras engendra uma dinâmica própria do público que ela atende. Quando nos referimos ao educando jovem e adulto, não nos reportamos a qualquer sujeito vivenciando a etapa de vida jovem ou adulta, e sim a um público particular e com características específicas: sujeitos que foram excluídos do sistema escolar (possuindo, portanto, pouca ou nenhuma escolarização); indivíduos que possuem certas peculiaridades socioculturais; sujeitos que já estão inseridos no mundo do trabalho; sobretudo, sujeitos que se encontram em uma etapa de vida diferente da etapa da infância (SOARES; PEDROSO, 2013, p. 252).

Assim, é reforçada a ideia de Freire (1996), que evidencia a necessidade de os docentes assumirem uma postura dialógica e dialética, possibilitando o desenvolvimento do ensino e da aprendizagem baseado na realidade vivida pelos alunos, jamais se reduzindo à simples transmissão de conhecimentos. Pois, mesmo com todas as dificuldades enfrentadas pelos alunos atendidos na Educação de Jovens e Adultos, a escola é vista como caminho para a ascensão e oportunidades, desenvolvendo competências e habilidades que proporcionam melhores condições de trabalho e vida.

Nesse sentido, compreendemos que o enfrentamento dos desafios da evasão escolar na modalidade EJA alia-se às diferentes formas com que os alunos são afetados pelas inúmeras situações que a vida os impõe. Assumimos que a dimensão dos afetos constitui, de maneira interdependente com a dimensão da cognição, as relações de ensino e aprendizagem. Tais relações são movidas pela necessidade, pelo desejo e pela paixão, tanto do professor quanto dos alunos. Freire (1996) afirma que:

\footnotetext{
Se não posso, de um lado, estimular os sonhos impossíveis, não devo negar a quem sonha o direito de sonhar. Lido com gente e não com coisa. E porque lido com gente, não posso, por mais que, inclusive, me dê prazer entregar-me à reflexão teórica e crítica em torno da própria prática docente e discente, recusar a minha atenção dedicada e amorosa a problemática mais pessoal deste ou daquele aluno ou aluna (FREIRE, 1996, p. 144).
}

Diante do exposto, realizamos uma pesquisa cujo objetivo foi investigar o que afeta os alunos da EJA, anos iniciais, de forma a potencializar a vontade de se manterem estudando, permanecendo na escola por mais tempo, impedindo, consequentemente, a evasão.

\section{O MÉTODO: o caminho percorrido}


O presente estudo trata-se de uma pesquisa empírica, de tipo explicativa, que busca aprofundar o conhecimento da realidade, explicando a razão e o porquê das coisas.

Assim, para estudar a Educação de Jovens e Adultos, faz-se necessário considerar as especificidades dos alunos atendidos, considerando que o adulto que procura essa modalidade da Educação Básica foi em algum momento de sua vida excluído social, cultural e economicamente do espaço escolar.

Nessa perspectiva, as relações estabelecidas no ambiente escolar são fundamentais para a aprendizagem dos alunos, tendo em vista que o processo de aprendizagem ocorre a partir das interações estabelecidas entre o sujeito e o objeto de conhecimento.

Como instrumentos para a produção do material empírico, foram utilizadas a observação nas salas de aula participantes do estudo e a técnica de grupo focal com os alunos. A pesquisa teve a aprovação do Comitê de Ética em Pesquisa com Seres Humanos, com número do registro na Plataforma Brasil, CAAE 15012419.4.0000.5481.

A pesquisa, em nível de Mestrado, foi desenvolvida no município de Campinas (SP) durante o ano de 2019 e teve como participantes alunos que estudavam em três classes descentralizadas, na Educação de Jovens e Adultos - anos iniciais, oferecidas pela Fundação Municipal para Educação Comunitária - FUMEC, da Região Sul. O território do município de Campinas é organizado em cinco grandes regiões - norte, sul, leste, noroeste e sudeste, e a modalidade EJA é oferecida em classes descentralizadas, tendo como referência o MOVA idealizado por Paulo Freire, para facilitar o acesso e a permanência dos alunos. As salas funcionam em locais e horários em que há demanda de alunos não alfabetizados, com mobiliário e material pedagógico oferecidos pela FUMEC, em espaços cedidos por escolas estaduais e municipais, Naves Mães, ${ }^{1}$ igrejas, instituições filantrópicas, centros comunitários, centros de convivência, dentre outros.

Foram realizadas observações da rotina educacional dos participantes, em suas atividades desenvolvidas em sala de aula. As sessões de observações aconteceram em período de aula, antecipadamente acordadas com as professoras, totalizando quatro visitas em cada uma das classes, e subsidiaram o roteiro da conversa nos grupos focais, que tiveram a própria pesquisadora como moderadora e foram realizados na própria sala de aula, ambiente bem familiar para os alunos. Todos os alunos assinaram o Termo de Consentimento Livre e Esclarecido (TCLE), bem como as professoras das classes selecionadas. Os critérios de escolha das classes para a participação na pesquisa foram: ter mais de 12 alunos com idade mínima de 18 anos; possuir quatro ou mais alunos matriculados desde 2017 (mais de dois anos) com a mesma professora; ter a presença de, no mínimo, um aluno que tenha parado por um semestre e retornado ao mesmo local, com a mesma professora; e contar com a permanência da professora no mesmo local, trabalhando na comunidade há mais de cinco anos.

Apresentamos neste texto o material produzido nos grupos focais. Foi realizado um encontro com o grupo de alunos de cada uma das três salas. O primeiro grupo focal contou com cinco participantes e o segundo e terceiro grupos tiveram 13 alunos em 
cada um. O número de participantes relaciona-se com o total de alunos presentes no dia da realização dos grupos focais. Inspiradas em Gatti (2012), solicitamos, como aquecimento, que cada participante dissesse em uma palavra o que representava a escola para si e, na sequência, foi encaminhada a conversa, com a seguinte questão disparadora: O que motiva a sua vinda à escola? A partir daí outras questões foram feitas, com o objetivo de explorar mais o que diziam sobre permanecer ou desistir de estudar. Os encontros foram gravados em áudio, com autorização prévia concedida pelo grupo.

A análise foi realizada por meio da elaboração de núcleos de significação, visando apreender os sentidos atribuídos pelos participantes para a permanência na EJA. Com base em Aguiar e Ozella (2013), extraímos das falas transcritas dos participantes o que os autores denominam pré-indicadores. Estes nos forneceram pistas sobre os temas abordados, que se constituíram nos indicadores, e o processo analítico final foi a construção, a partir dos indicadores, dos núcleos de significação.

\section{A TRAJETÓRIA DE ESCOLARIZAÇÃO: OS MODOS DE PENSAR E DE SENTIR DOS ALUNOS PARA SE MANTEREM, OU NÃO, DENTRO DA ESCOLA}

Foram construídos três núcleos de significação, que evidenciam como os participantes significam o que os afeta ou afetou de forma a potencializar a vontade de se manterem estudando, permanecendo na escola por mais tempo, impedindo, consequentemente, a evasão. A seguir discorremos sobre cada um dos núcleos.

Núcleo 1: As histórias de impossibilidades

O primeiro núcleo se refere aos acontecimentos e aos sentimentos decorrentes de experiências pessoais que levaram os participantes da pesquisa à impossibilidade de frequentar a escola e/ou dar continuidade aos estudos, tornando-se evidentes os impedimentos e arrependimentos. Todos os participantes compartilharam histórias pessoais resgatando os fatores que os impediram de frequentar a escola na idade considerada adequada ou depois de adulto. Os fatores mais recorrentes se referem a impedimentos relacionados à família, por exemplo, ter que cuidar de algum parente próximo ou por imposição de familiar que impedia a experiência escolar. Neste último caso, as mulheres são as que mais relataram a dificuldade imposta pela figura masculina em suas vidas, representada pelo pai ou pelo marido.

Nessas histórias de impedimentos é evidenciada uma posição de conformidade e aceitação das dificuldades encontradas para acessar e permanecer na escola. Segundo Freire (2019), o sujeito adulto é capaz de se perceber na realidade que lhe parecia ser inflexível e aceitá-la. O sujeito da EJA toma consciência da situação de opressão, e a assume como verdade, justificando a aceitação e posição de conformidade.

Mas tenho um marido que não gosta que eu venho para a escola. Aí
ele fala para que ir para a escola depois de velha? Aí eu falo para ele
que tem gente de idade que aprende né. E ele não gosta que eu
venho para a escola. Mas meu marido continua falando não vai para
a escola não, não vai estudar não, você não vai aprender nada. Eu já
desisti, por causa do meu marido. Eu já desisti, já voltei. Ele disse 
que se eu saísse ele ia ficar contente (3AL, grupo focal, 18 set. $2019)^{2}$.

Na minha infância eu ajudava a cuidar dos meus irmãos. Depois foi a vez de cuidar dos filhos (2MJ1, grupo focal, 10 set. 2019).

E meus pais davam preferência para o trabalho. E estudo naquele tempo, eles viviam quase sem estudo. E eles achavam que nós tínhamos que seguir o mesmo caminho deles, né? (3M1, grupo focal, 18 set. 2019).

Trabalhava de dia, estudava a noite. Não dava. Aí eu parei, hoje me arrependo, deveria ter insistido mais. Eu me arrependo de não ter me forçado para poder estudar... (1MD1, grupo focal, 5 set. 2019).

As histórias de insucesso e impossibilidades envolvem os sentidos atribuídos pelos participantes a respeito do que os impedia de frequentar a escola na época em que eram crianças e, também, na vida adulta. Com as falas, torna-se possível evidenciar que as condições socioeconômicas da família junto com uma educação muito marcada pelo patriarcado acabam discriminando a mulher e impedindo que ela estude e busque um caminho de ascensão, tanto educacional quanto profissional. Essas falas mostram também como as condições financeiras mais difíceis da família acabam sendo um impedimento, pois as pessoas precisam trabalhar na roça desde muito novas para o sustento da família, reforçando a ideia de que sobrevivência e estudo não combinam.

Além disso, nas falas dos participantes da pesquisa, torna-se evidente que, ainda, segundo Freire (2019),

Até o momento em que os oprimidos não tomem consciência das razões de seu estado de opressão, "aceitam" fatalistamente a sua exploração. Mais ainda, provavelmente assumam posições passivas, alheadas, com relação a necessidade de sua própria luta pela conquista da liberdade e de sua afirmação no mundo (FREIRE, 2019, p. 71).

Paulo Freire $(1996,2019)$, em suas obras, nos proporciona uma ampla reflexão sobre a alfabetização de adultos, a alfabetização como ato de conhecimento, como ato criador e como ato político, trazendo que:

[...] é como seres transformadores e criadores que os homens, em suas permanentes relações com a realidade, produzem, não somente os bens materiais, as coisas sensíveis, os objetos, mas também as instituições sociais, suas ideias, suas concepções (FREIRE, 2019, p. 128).

Assim, a educação é a mola propulsora na transformação da realidade da vida do sujeito, pois se apresenta como um caminho de possibilidade de ascensão pessoal e profissional. As histórias de impossibilidades nos levam à confirmação das marcas das 
dificuldades de acesso e permanência na escola, bem como à confirmação da educação como um direito público e subjetivo que não foi garantido. Histórias marcadas por problemas familiares, dificuldades socioeconômicas, necessidade de trabalho na infância, impossibilidade de estudo para dedicação e cuidado de filhos e familiares, impedimento pelo cônjuge, entre outros, constituem-se como justificativas para o impedimento de acesso e da permanência na escola.

Diante disso, podemos afirmar que a Educação de Jovens e Adultos é uma modalidade de educação muito importante, pois tem a função reparadora, equalizadora e qualificadora, destinada a quem não teve oportunidade de estudar na idade considerada adequada, como citado no Parecer CNE/CEB nº 11/2000.

Núcleo 2: A relação com a escola e as práticas pedagógicas

O núcleo 2 explora os sentidos atribuídos pelos participantes às relações construídas com a escola e com as práticas pedagógicas. Retrata a vivência dos participantes da pesquisa com a escola durante a infância e a adolescência e com as práticas pedagógicas vividas no passado até os dias de hoje, bem como as suas influências na história escolar de cada indivíduo. As experiências vividas na escola marcaram as relações com o estudo e os significados atribuídos a ele.

A escola tem valor, é muito importante, muda a vida da gente. A escola para mim é muito boa (1J1, grupo focal, 5 set. 2019).

A escola foi conhecimento, crescimento, possibilidade de uma vida melhor (1J2, grupo focal, 5 set. 2019).

Primeiramente queria falar que eu estou muito feliz de estar aqui hoje. Para mim está sendo um novo caminho. Estou muito feliz de estar aqui. Eu gosto de tudo. Antes eu não aprendia, agora estou aprendendo, eu sei que consigo (3S, grupo focal, 18 set. 2019).

Através da professora que eu estou conseguindo alguma coisa... ler... então eu fico muito feliz de saber alguma coisinha, eu chego em casa e conto para os meus filhos, para o meu esposo, porque eu achava muito difícil, para a gente que não sabe (1ML1, grupo focal, 5 set. 2019).

Aprendi muito com a professora. Quando eu cheguei, eu falava "eu não sei, eu não sei". Ela falava "sabe, vai aprender". Ela é uma pessoa maravilhosa. É uma pessoa muito boa (2MJ1, grupo focal, 10 set. 2019).

Observa-se, a partir deste núcleo, a validação dos conhecimentos e saberes que são construídos na relação com as professoras. Freire $(2019$, p. 28) destaca que:

[...] a alfabetização não é um jogo de palavras, é a consciência reflexiva da cultura, a reconstrução crítica do mundo humano, a abertura de novos caminhos, o projeto histórico de um mundo comum, a bravura de dizer a sua palavra. A alfabetização, portanto, 
é toda a pedagogia: aprender a ler é aprender a dizer a sua palavra. E a palavra humana imita a palavra divina: é criadora (FREIRE, 2019, p. 28).

Nas falas dos participantes, evidencia-se a gratidão e valorização da possibilidade de pertencer ao espaço educativo e o quanto a escola é vista como possibilitadora do fortalecimento dos sujeitos em relação aos seus anseios quanto à sua trajetória social. Alves e Backers (2016) argumentam que o papel do educador da EJA é abrir os caminhos, ampliando possibilidades ao educando.

Assim, na prática, o educador deve expor aos alunos jovens e adultos que é possível mudar transformando sua realidade, sua história. E isso só é possível para quem se deixar acreditar, para quem quer aprender e também quer ensinar; é por isso que o educador precisa observar a sua prática, para que ela possa atender às necessidades do seu aluno, contribuir para sua transformação e, acima de tudo, respeitando suas crenças (ALVES; BACKERS, 2016, p. 104).

Nesse sentido, os participantes da pesquisa, quando verbalizam seus sentimentos com relação à escola de EJA que vivenciam, dizem sobre seu entendimento, como se sentem respeitados e inseridos no mundo letrado, como foram afetados pela escola e pelas relações nela existentes. Segundo Freire (1996),

Como educador preciso ir "lendo" cada vez melhor a leitura de mundo que os grupos populares com quem trabalho fazem de seu contexto imediato e do maior de que o seu é parte. O que quero dizer é o seguinte: não posso de maneira alguma, nas minhas relações político-pedagógicas com os grupos populares, desconsiderar seu saber de experiência feito. Sua explicação do mundo de que faz parte a compreensão de sua própria presença no mundo. E isso tudo vem explicitando ou sugerido ou escondido no que chamo de "leitura do mundo", que precede sempre a "leitura da palavra" (FREIRE, 1996, p. 81).

A leitura de mundo está relacionada às experiências de vida dos sujeitos. Quando o educador consegue construir práticas educativas partindo da leitura de mundo dos alunos, conseguindo construir significados para compreender a própria condição de vida, possibilita a tomada de consciência e consegue promover aprendizagens significativas. Essa prática possibilita ler o mundo de maneira mais ampla e mais articulada às relações, condições e possibilidades. Freire nos remete à importância do interesse do educador pelo educando e seus saberes, estabelecendo uma relação de ensino e aprendizagem mais próxima, na qual o educador demonstre interesse em conhecer seus educandos, suas características, suas experiências, suas expectativas, além de suas necessidades de aprendizagem. 
No entanto, há marcas da exclusão que ainda ecoam com força nas formas de os alunos se perceberem, em razão de experiências que os afetaram, mobilizando sentimentos de medo, insegurança, de incapacidade e de inferioridade.

Quando a professora falava "matemática", nossa, eu passava mal. E até hoje eu não gosto. Por causa que eu fiquei com trauma (2R, grupo focal, 10 set. 2019).

Eu tive a oportunidade e não fui por preguiça, na época. $E$ aí eu estudei até o $4^{\circ}$ ano, né, e depois não conclui. [...] Aí fui para o MOBRAL. Ai na época do MOBRAL eu ia para a escola estudar, mas não entrava na minha cabeça. Ao invés de ir para a escola ia para o cinema, saia... (3N, grupo focal, 18 set. 2019).

Paulo Freire (2019) evidencia que:

De tanto ouvirem de si mesmos que são incapazes, que não sabem nada, que não podem saber, que são enfermos, indolentes, que não produzem em virtude de tudo isso, terminam por se convencer de sua "incapacidade" (FREIRE, 2019, p. 69).

Como foi retratado, a escola é um lugar fundamental na vida dessas pessoas que são o público da EJA. No espaço da escola é que as desigualdades podem ser minimizadas, que as oportunidades podem ser para todos. Por esses motivos, precisamos que políticas públicas sejam criadas pensando em atender as especificidades desse público.

Núcleo 3: A relação com as práticas de letramento: as possibilidades de participação

O terceiro núcleo se refere à relação com as práticas de letramento e as possibilidades de participação social. Traz as concepções e os sentimentos que envolveram as experiências pessoais dos participantes, as expectativas que têm sobre o estudo e as mudanças que percebem em si mesmos em relação ao que estão aprendendo. Destacaram-se as possibilidades de ampliação da participação social, inserindo-se de maneira mais efetiva no mundo. Frequentar a escola remete à possibilidade de se desenvolver, de conseguir uma vida melhor, ampliando os horizontes.

Porque é muito bom você sair de casa, você chegar num lugar, arrumar um emprego, você vai assinar um papel e você não sabe. Então eu não vou desistir não (3V, grupo focal, 18 set. 2019).

Fui fazer teste para habilitação [de motorista] e não passei. Não tive condições de passar... Aí eu pensei "não sou pior que os outros para todo mundo ter e eu não tenho". Sem um carrinho para dirigir tava sendo muito difícil pra mim. Aí eu enfrentei aqui. A canseira bate é pesada, aí tem que resistir (3E, grupo focal, 18 set. 2019). 


\begin{abstract}
Antes eu não era nada, hoje eu entendo de tudo. Porque eu não sabia mexer num celular, hoje eu sei. Nossa, eu aprendi muita coisa, mesmo. Ler, eu sabia mais ou menos. E eu estou muito feliz, porque eu acho assim, "eu existo" "eu sou cidadã". [...] Mas eu aprendi a ler e a escrever. Hoje eu escrevo e consigo ler (2M2, grupo focal, 10 set. 2019).
\end{abstract}

A busca pela EJA de fato é marcada pela pretensão de novas possibilidades, tanto de mobilidade social como de possibilidade de emprego. O fato de o aluno não se sentir reconhecido como pertencente ou merecedor de algo por não saber ler e escrever é profundamente excludente. Assim, defende-se a importância do papel social que a EJA ocupa na vida desse público.

Freire (1996) traz contribuições profícuas para essa reflexão ao considerar que:

[...] a educação é uma forma de intervenção no mundo. Intervenção que além do conhecimento dos conteúdos bem ou mal ensinados e/ou aprendidos implica tanto o esforço de reprodução da ideologia dominante quanto o seu desmascaramento. Dialética e contraditória, não poderia ser a educação só uma ou só a outra dessas coisas. Nem apenas reprodutora nem apenas desmascaradora da ideologia dominante (FREIRE, 1996, p. 98).

Para o público-alvo da EJA, a educação é transformação social, é possibilidade de mudança de vida, é ressignificação de saberes. Pela educação, o sujeito se sente pertencente a um grupo. É através da educação que ele cria, recria, significa, se constrói e se reconstrói. Estão aí os motivos para permanecerem estudando:

O que me faz continuar estudando é que uma vez eu fui no banco pagar uma conta no horário de almoço eu não sabia tirar um estrato no banco para eu pagar. Vim embora sem tirar aquele estrato. Vim muito triste chorando dentro do ônibus (2MJ1, grupo focal, 10 set. 2019).

Eu fui fazer uma ficha na cidade também e eu achei que fosse um papel em branco. A moça disse "moço, você não vai fazer a ficha?", eu disse "moça eu não sei nem ler". E ela disse "tem que fazer a ficha para trabalhar, eu não posso fazer não, tem que ser você". Aí eu levantei e fui embora. Quem não sabe ler e nem escrever, nessa terra aqui, é muito difícil. Um ônibus a gente não sabe, tem que perguntar "que ônibus que é aquele lá?" É muito difícil ter que perguntar para os outros (3E, grupo focal, 18 set. 2019).

Até que certo dia eu fui fazer uma entrevista e a moça pediu para eu preencher e eu preenchi. Aí ela falou "agora você faz uma carta". Aí eu falei para ela, "mas eu tenho dificuldade de escrever, eu não consigo escrever". Aí ela falou "se vira". Ai na hora eu deixei os papéis e saí. Foi muito triste. Então eu tenho o apoio da minha família (3S, grupo focal, 18 set. 2019). 
Ao mesmo tempo em que os participantes da pesquisa relatam expectativas positivas com relação a frequentar o espaço educativo, eles carregam uma percepção de si marcada pelo insucesso, fracasso, dificuldades e desafios a serem superados. Os participantes da pesquisa tomam para si a responsabilidade do fracasso de terem tentado em algum momento e não ter dado certo, o que torna o esforço para o sucesso muito mais recompensador. Eles têm a percepção da evolução das aprendizagens e se motivam com as conquistas.

Para a superação dos desafios e das dificuldades, Freire (1996) defende a educação emancipatória:

Educação que possibilitasse ao homem a discussão corajosa de sua problemática. E sua inserção nessa problemática. Que o advertisse dos perigos de seu tempo, para que, consciente deles, ganhasse a força e a coragem de lutar, ao invés de ser levado e arrastado à perdição do seu próprio "eu", submetido às prescrições alheias. Educação que o colocasse em diálogo constante com o outro. Que o predispusesse a constantes revisões. À análise crítica dos seus "achados". A certa rebeldia, no sentido mais humano da expressão (FREIRE, 1996, p. 96).

Busca-se assim, através da educação, a transformação da vida, a ampliação de suas possibilidades e a significação de seus conhecimentos pelas interações sociais. Desse modo, os alunos da EJA são sujeitos histórico-culturais com saberes, com cultura e, também, com projetos de vida. Carregam marcas das suas experiências de vida e a escola é vista como parte do projeto de transformação da vida do aluno.

A produção do conhecimento se constrói nas relações estabelecidas entre os sujeitos e a cultura. Assim, a maneira como a mediação existente nessa relação acontece é um fator importante. Para os alunos da EJA, frequentar a escola é fazer parte de um grupo social; é ter a possibilidade de aprender a ler, a escrever, a calcular, a ressignificar seus conhecimentos; é possibilidade de ter seus conhecimentos valorizados pelo outro; é ser visto e reconhecido.

Apresentamos e discutimos os três núcleos de significação que nos ajudaram a pensar o que afeta os alunos da EJA, anos iniciais, de forma a potencializar a vontade de se manterem estudando, permanecendo na escola por mais tempo, impedindo, consequentemente, a evasão. Os participantes da pesquisa demonstraram que se esforçam muito para estar na escola e valorizam poder estar lá. Chegam cansados, não querem faltar, ficam preocupados quando adoecem e não podem ir, não querem perder essa chance de estar na escola. O que os leva a ficar é a história pessoal de cada um e o modo como as experiências na sala de aula vão afetando e transformando as suas vidas. Aprender a ler e a escrever é a condição central, mas para se efetivar como caminho de emancipação, precisa se assumir "a alfabetização como ato de conhecimento, como ato criador e como ato político [sendo] um esforço de leitura do mundo e da palavra" (FREIRE, 1989, p. 30).

A ideia de Freire (1996) nos faz retomar o que foi tratado nos núcleos, em que o ensino e aprendizagem da leitura, escrita e cálculos não podem ser resumidos apenas em conteúdo, uma vez que eles proporcionam aos indivíduos a possibilidade de acesso a um mundo de oportunidades. Dessa forma, ainda referenciando o autor, 


\begin{abstract}
Como prática estritamente humana jamais pude entender a educação como experiência fria, sem alma, em que os sentimentos e as emoções, os desejos, os sonhos devessem ser reprimidos por uma espécie de ditadura racionalista. Nem tampouco jamais compreendi a prática educativa como uma experiência a que faltasse rigor em que se gera a necessária disciplina intelectual (FREIRE, 1996, p. 145-146).
\end{abstract}

Neste momento, podemos retomar a indissociabilidade entre as dimensões afetiva e cognitiva. O rigor mencionado por Freire (1996) concretiza-se na aprendizagem propriamente dita e, conforme Tassoni e Leite (2011),

\begin{abstract}
Considerando o professor um dos mediadores na sala de aula, suas ações têm por objetivo a aprendizagem do aluno. Nessas ações mediadoras, o aluno entra em contato com modos de pensar, agir e sentir em relação ao conhecimento envolvido e a situação em si. Nessa dinâmica, a forma como o aluno significa a ação do professor revela uma atitude afetiva (TASSONI; LEITE, 2011, p. 83).
\end{abstract}

As relações existentes na escola, as mediações, os objetivos de ensino e as ações planejadas no ambiente escolar afetam diretamente o educando, mas também o fazem os apelos do trabalho, os sentimentos de exclusão e o desejo de exercício da cidadania.

\title{
CONSIDERAÇÕES FINAIS
}

Considerando a sala de aula como um lugar de encontros e experiências intensas, os afetos vão se referir à percepção que cada aluno constrói dessas interações que, por sua vez, vão proporcionando mudanças nos sujeitos, que se percebem aprendendo, entendendo o funcionamento da escrita, conseguindo ler, conseguindo resolver problemas, compreendendo os conteúdos, sentindo-se capazes. Quando os alunos da EJA têm a compreensão de que os conhecimentos que estão adquirindo na escola podem ser utilizados fora do ambiente escolar, percebem-se também com um desempenho diferente na sociedade. O ambiente escolar, além de proporcionar aprendizagens, também proporciona inserção cultural.

Assim, foram evidenciados fatores de âmbito pessoal - especialmente as demandas familiares, como cuidar de filhos, irmãos, o cuidado com a casa e com o marido, questões pessoais de saúde, a dominação da figura masculina impedindo que a mulher estude como fortes obstáculos à permanência na escola. Mas também a família como influenciadora da permanência - o encorajamento dos netos e dos filhos. No âmbito do trabalho, nas histórias relatadas pelos participantes, observamos tanto influências de impedimento, dificultando o acesso e a permanência, em razão da necessidade de subsistência e da incompatibilidade entre trabalhar e estudar, do cansaço gerado pela pesada jornada, as longas distâncias a serem percorridas entre casa, trabalho e escola. Mas, ao mesmo tempo, esses fatores impulsionam a busca pelos estudos, por possibilitarem mobilidade na carreira, por possibilitarem inserção cultural e profissional.

Inter-Ação, Goiânia, v.46, n. ed.especial, p. 1068-1085, set. 2021. Disponível em: <http://dx.doi.org/10.5216/ia.v46ied.especial.68193> 


\section{PAULO FREIRE AND THE YOUTH AND ADULT EDUCATION: MEANINGS ATTRIBUTED BY STUDENTS FOR STAYING IN EJA}

ABSTRACT: Taking Paulo Freire's legacy as a reference, we present a research that aimed to investigate what affects EJA students, early years, in order to enhance the desire to keep studying, staying in school for longer, minimizing evasion. This is an empirical research conducted in three classes of EJA (early years), in the city of Campinas / SP. The methodological procedures involved observation in the classroom and the realization of focus groups with 31 students. The analysis explored the meanings attributed by the participants to their personal and school experiences. The factors that contribute to staying at EJA are: the desire for cultural insertion and the perception that they are learning. The influences of family and work constituted both reasons for impediments and permanence.

KEYWORDS: Affections and EJA. Teaching and Learning. School and Cultural Insertion. Permanence and Evasion.

PAULO FREIRE Y LA EDUCACIÓN DE JÓVENES Y ADULTOS: SENTIDOS ASIGNADOS PARA LOS ESTUDIANTES POR LA PERMANENCIA EN EJA

RESUMEN: Tomando como referencia el legado de Paulo Freire, presentamos una investigación que tuvo como objetivo investigar qué afecta a los estudiantes de EJA, los primeros años, con el fin de potenciar el deseo de seguir estudiando, permanecer más tiempo en la escuela, minimizando la deserción. Se trata de una investigación empírica realizada en tres clases de EJA (primeros años), en la ciudad de Campinas/SP. Los procedimientos metodológicos involucraron la observación en el aula y la realización de grupos focales con 31 alumnos. El análisis exploró los significados atribuidos por los participantes a sus experiencias personales y escolares. Los factores que contribuyen a la permanencia en EJA son: el deseo de inserción cultural y la percepción de que están aprendiendo. Las influencias de la familia y el trabajo constituyeron tanto motivos de impedimentos como de permanencia.

PALABRAS CLAVE: Afectos y EJA. Enseñando y Aprendiendo. Inserción Escolar y Cultural. Permanencia y Evasión.

\section{NOTAS}

1 - Naves Mãe são escolas de Atendimento Especial à Educação Infantil, que têm como objetivo ampliar a oferta de vagas em parceria com instituições de direito privado sem fins lucrativos, ou seja, com instituições comunitárias, confessionais e filantrópicas. 
2 - Para preservar a identidade dos participantes, utilizamos uma combinação de números e letras. O número inicial refere-se ao grupo focal do qual o sujeito participou. As letras e os números finais, estes incluídos quando necessário, identificam cada um dos participantes.

*Artigo elaborado a partir da dissertação de mestrado de J. R. S. Buzioli, intitulada "Afetividade e permanência na Educação de Jovens e Adultos - anos iniciais". Pontifícia Universidade Católica de Campinas 2021.

**Este estudo foi parcialmente financiado pela Coordenação de Aperfeiçoamento de Pessoal de Nível Superior - Brasil (CAPES).

\section{REFERÊNCIAS}

AGUIAR, W. M. J. de; OZELLA, S. Apreensão dos sentidos: aprimorando a proposta dos núcleos de significação. Rev. Bras. Estud. Pedagog. Brasília, v. 94, n. 236, p. 299-322, abril 2013. DOI: https://doi.org/10.1590/S2176-66812013000100015.

ALBUQUERQUE, E. B. C; LEAL, T. F. A alfabetização de jovens e adultos em uma perspectiva de letramento. 3. ed. Belo Horizonte: Autêntica, 2006.

ALMEIDA, M. L. S. Sujeitos não-alfabetizados: sujeitos de direitos, necessidades e desejos. In: SOARES L. (org.). Aprendendo com a diferença: estudo e pesquisa em educação de jovens e adultos. Belo Horizonte: Autêntica, 2003. p. 65-90. Disponível em: $<$ https://grupoautentica.com.br/autentica/livros/aprendendo-com-a-diferenca-estudose-pesquisas-em-educacao-de-jovens-e-adultos/21>. Acesso em: 13 fev. 2020.

ALVES, C. F.; BACKES, D. I. M. Educação de Jovens e Adultos - EJA: Um olhar para os alunos dessa modalidade de ensino. Revista Prâksis, Novo Hamburgo, v. 1, p. 98-111, julho, 2016. DOI: https://doi.org/10.25112/rp.v1i0.437.

BEISIEGEL, C. R. Paulo Freire. Recife: Fundação Joaquim Nabuco, Editora Massangana, 2010.

BRASIL. Constituição federal 1988. Constituição da República Federativa do Brasil: promulgada em 5 de outubro de 1988. Disponível em: <https://www2.senado.leg.br/bdsf/bitstream/handle/id/518231/CF88_Livro_EC91_2016 .pdf>. Acesso em: 13 ago. 2020.

FERRARO, A. R. Analfabetismo. Glossário CEALE. Disponível em: <http://www.ceale.fae.ufmg.br/app/webroot/glossarioceale/verbetes/analfabetismo $>$. Acesso em: 21 dez. 2020.

FREIRE, P. Pedagogia do Oprimido. 71. ed. Rio de Janeiro/ São Paulo: Paz e Terra, 2019. 
BUZIOLI, J. R. de S.; TASSONI, E. C. M

FREIRE, P. Pedagogia da Autonomia: saberes necessários à prática educativa. São Paulo: Terra e Paz, 1996.

FREIRE, P. A importância do ato de ler. Col. Polêmicas do nosso tempo. Editora Cortez, São Paulo, 1989.

FREIRE, P. Educação como prática da liberdade. Rio de Janeiro: Paz e Terra, 1975.

FUMEC. Fundação Municipal para Educação Comunitária. Disponível em: <http://www.fumec.sp.gov.br/>. Acesso em: 15 abr. 2019.

GATTI, B. A. Grupo focal na pesquisa em ciências sociais e humanas. Brasília: Liber Livro, 2012.

HADDAD, S. DI PIERRO, M. C. Escolarização de jovens e adultos. Revista Brasileira de Educação. São Paulo, s. v., n. 14, p. 108-130, 2000. DOI: <https://doi.org/10.1590/S141324782000000200007>. Acesso em: 2 ago. 2020.

IBGE. EDUCA. Disponível em: <https://educa.ibge.gov.br/jovens/conheca-obrasil/populacao/18317-educacao.html>. Acesso em: 21 dez. 2020.

MOVA-BRASIL. Disponível em: <https://www.paulofreire.org/programas-eprojetos/projeto-mova-brasil.>Acesso em: 26 fev. 2021.

PARECER CNE/CBE 11/2000. Ministério da Educação. Conselho Nacional de Educação/ Câmara de Educação Básica. Diretrizes Curriculares Nacionais para a Educação de Jovens e Adultos. Brasília. 2000.

SOARES, L. J. G.; PEDROSO, A. P. F. Dialogicidade e a formação de educadores na EJA: as contribuições de Paulo Freire. ETD - Educação Temática Digital, Campinas-SP, v. 15, n. 2, p. 250-263, maio/ago. 2013. DOI: 10.20396/etd.v15i2.1281. Disponível em: $<$ https://periodicos.sbu.unicamp.br/ojs/index.php/etd/article/view/1281>. Acesso em: 14 set. 2020.

TASSONI, E. C. M.; LEITE, S. A. S. Um estudo sobre emoções e sentimentos na aprendizagem escolar. Comunicações, Piracicaba, v. 18, n. 2, p. 79-91, 2011. DOI: http://dx.doi.org/10.15600/2238-121X/comunicacoes.v18n2p79-91.

Josiane Regina de Souza Buzioli: Mestra em Educação pela Pontifícia Universidade Católica de Campinas. Licenciada em Pedagogia pela Pontifícia Universidade Católica de Campinas. Diretora Educacional, efetiva, da Fundação Municipal para Educação Comunitária de Campinas - FUMEC.

Orcid: https://orcid.org/0000-0003-2934-1928

E-mail: josianebuzioli@gmail.com 
Elvira Cristina Martins Tassoni: Doutora e Mestra em Educação pela Unicamp. Licenciada em Pedagogia pela Pontifícia Universidade Católica de Campinas. Docente permanente do Programa de Pós-Graduação em Educação, Centro de Ciências Humanas e Sociais Aplicadas da Pontifícia Universidade Católica de Campinas.

Orcid: https://orcid.org/0000-0002-8968-3981

E-mail: cristinatassoni@puc-campinas.edu.br

Este periódico utiliza a licença Creative Commons Attribution 3.0, para periódicos de acesso aberto (Open Archives Initiative - OAI). 